\title{
Differential regulation of endothelium behavior by progesterone and medroxyprogesterone acetate
}

\author{
Pablo H Cutini ${ }^{1,2}$, Adrián E Campelo ${ }^{1,2}$ and Virginia L Massheimer ${ }^{1,2}$ \\ ${ }^{1}$ Cátedra de Bioquímica Clínica II, Departamento de Biología, Bioquímica y Farmacia, Universidad Nacional \\ del Sur (UNS), San Juan 670, B8000ICN, Bahía Blanca, Argentina \\ ${ }^{2}$ Consejo Nacional de Investigaciones Científicas y Técnicas (CONICET), Argentina, Buenos Aires, Argentina
}

Correspondence should be addressed to V L Massheimer Email massheim@uns.edu.ar

\begin{abstract}
Medroxyprogesterone acetate (MPA) is a synthetic progestin commonly used in hormone replacement therapy (HRT). The aim of this research was to study and compare the effect of progesterone $(\mathrm{Pg})$ and MPA on the regulation of cellular events associated with vascular homeostasis and disease. Platelet adhesion to endothelial cells (ECs), nitric oxide (NO) production, and cell migration were studied using murine ECs in vitro exposed to the progestins. After 7 min of treatment, MPA significantly inhibited NO synthesis with respect to control values; meanwhile, Pg markedly increased vasoactive production. In senile ECs, the stimulatory action of Pg decreases; meanwhile, MPA maintained its ability to inhibit NO synthesis. The presence of RU486 antagonized the action of each steroid. When ECs were preincubated with PD98059 (MAPK inhibitor) or chelerythrine (protein kinase C (PKC) inhibitor) before Pg or MPA treatment, the former totally suppressed the steroid action, but the PKC antagonist did not affect NO production. In the presence of a PI3K inhibitor (LY294002), a partial reduction in Pg effect and a reversal of MPA action were detected. Using indomethacin, the contribution of the cyclooxygenase (COX) pathway was also detected. On platelet adhesion assays, Pg inhibited and MPA stimulated platelet adhesion to ECs. Under inflammatory conditions, Pg prevented platelet adhesion induced by lipopolysaccharide (LPS); meanwhile, MPA potentiated the stimulatory action of LPS. Finally, although both steroids enhanced migration of ECs, MPA exhibited a greater effect. In conclusion, the data presented in this research provide evidence of a differential regulation of vascular function by $\mathrm{Pg}$ and MPA.
\end{abstract}

\section{Key Words}

- cell migration

- medroxyprogesterone acetate

- nitric oxide

- progesterone

- vascular tissue

\section{Introduction}

The endothelium is the main regulator of vascular physiology that contributes to maintaining vascular tone and non-thrombogenic properties of the endothelial surface. Endothelial nitric oxide (NO) is a key factor in vascular homeostasis with antiatherogenic and antithrombotic
Journal of Endocrinology

(2014) 220, 179-193 properties. NO is a potent vasodilator that prevents platelet aggregation (Ignarro 1989) and leukocyte adhesion to the endothelium (Tsao et al. 1995) and decreases the expression of proinflammatory genes (Harrison et al. 2006). Several cardiovascular risk factors 
such as oxidative stress, alterations in plasmatic lipid profile, hypertension, viral infections, and diabetes mellitus promote endothelial dysfunction and consequently vascular diseases, mainly atherosclerosis. The genesis of atheromatous lesions has a multifactorial pattern characterized by impaired synthesis of vasoactive molecules (NO and prostacyclin), enhanced synthesis and expression of cell adhesion molecules (CAMs) involved in leukocyte infiltration and platelet adhesion, as well as an altered profile of cell proliferation and migration. The initial response to vascular injury includes activation, adhesion, and aggregation of platelets to endothelium, which are the events that release cytokines and enhance leukocyte recruitment (Ross 1999). In vascular diseases, endothelial cell (EC) turnover is altered (Choy et al. 2001). After endothelium damage, vessel repair is achieved by migration and proliferation of adjacent ECs (Cartwright et al. 2000, Moreno et al. 2009).

Menopause hypoestrogenism represents a physiological risk factor for cardiovascular disease, which is attributed to the loss of $17 \beta$-estradiol $\left(\mathrm{E}_{2}\right)$ cardioprotection. However, besides the decrease of circulating E2 levels, synthesis of ovarian progesterone $(\mathrm{Pg})$ is also affected during menopause. Hormone replacement therapy (HRT) based on estrogen, or combined with natural or synthetic progestins like medroxyprogesterone acetate (MPA), has emerged as an option to relieve the signs and symptoms associated with menopause. Although there is a large body of information derived from in vitro experimental studies that confer a relevant cardioprotective action to $\mathrm{E}_{2}$, this cannot be translated into health benefit when HRT is applied to postmenopausal women. This raises the controversy about the risk/benefit of HRT with respect to cardiovascular disease.

Historically, progestins were included in the HRT protocols to counteract the endometrial dysplasia caused by $E_{2}$. It has been reported that administration of MPA improves the effectiveness of HRT (Manson et al. 2003). However, other studies have shown that coadministration of progestins blocks the atheroprotective effect of estrogen (Sitruk-Ware 2000). The secondary cardiovascular prevention study Heart and Estrogen/progestin Replacement Study showed that HRT performed by oral administration of conjugated equine estrogen (CEE) and MPA for 4 years was not able to reduce the incidence of coronary events and, in turn, increased the risk of thromboembolic events in postmenopausal women with established coronary artery disease (Hulley et al. 1998, Grady et al. 2002). Indeed, in the Women's Health Initiative trial, CEE plus MPA administration to healthy postmenopausal women resulted in a substantial increase in the risk of myocardial infarction (Rossouw et al. 2002). In contrast, another study also performed in healthy postmenopausal women showed that oral administration of $\mathrm{E}_{2}$ plus Pg improved circulating levels of coagulation factors and vascular health (van Baal et al. 1999).

Vascular function is regulated by several hormones and factors including sex steroids. Both ECs and vascular smooth muscle cells (VSMCs) possess estrogen receptor and Pg receptor (PgR; Joswig et al. 1999, Vazquez et al. 1999). Current knowledge about the biochemical action of natural Pg and other progestins at the vascular level is quite low in contrast to the large amount of evidence reported regarding $E_{2}$. In recent years, potential vascular effects of $\mathrm{Pg}$ have been described. In rabbit coronary arteries and rat aorta, Pg induces endotheliumindependent vasorelaxation (Jiang et al. 1992). Moreover, Pg regulates vascular cell growth (Glusa et al. 1997, Simoncini et al. 2003) and inhibits expression of adhesion molecules induced by tumor necrosis factor- $\alpha$ (TNF- $\alpha$ ) and lipopolysaccharide (LPS) (Glusa et al. 1997, Otsuki et al. 2001, Simoncini et al. 2004). We have previously demonstrated that in rat aortic tissue, Pg non-genomically induces NO synthase (NOS) and cyclooxygenase (COX) stimulation through a mechanism of action that involves MAPK and phosphatidylinositol-3-kinase (PI3K) signaling pathways and a cross talk between NOS and COX systems. The rapid action of the steroid also includes inhibition of platelet aggregation (IPA) dependent on NOS and phospholipase C (PLC) transduction systems (Mendiberri et al. 2006). The fast effects elicited by the hormone are required for the regulation of EC growth (Cutini et al. 2009). Pg also enhances cell proliferation, migration, and apoptosis of VSMCs. The regulation of muscle cell growth matched with the two-step model of steroid action that integrates genomic and non-genomic actions (Cutini et al. 2009, Cutini \& Massheimer 2010).

There is evidence in the literature that Pg and MPA are not equivalent in terms of molecular signaling in human and murine vascular tissues. It has been reported that Pg and MPA activate different signaling events in vitro (L'hermite et al. 2008). MPA and other synthetic progestins exert different inflammatory and anti-inflammatory effects in vitro when compared with Pg (Simoncini et al. 2004). Therefore, the aim of this research was to study and compare the effect of Pg and MPA on the regulation of cellular events associated with vascular homeostasis and disease: platelet adhesion to ECs, NO production, and cell migration.

Published by Bioscientifica Ltd. 


\section{Materials and methods}

\section{Materials}

Pg was obtained from Calbiochem-Novabiochem International (San Diego, CA, USA). Griess reagents were purchased from Britania Laboratories (Buenos Aires, Argentina). Trypsin/EDTA $(10 \times)$, L-glutamine $(100 \times)$, amphotericin B $(0.25 \mathrm{mg} / \mathrm{ml})$, penicillin/streptomycin $(100 \times)$, and FCS were obtained from PAA Laboratories (Pasching, Austria). DMEM, MPA, N-nitro-L-arginine methyl ester (L-NAME), and all other reagents were purchased from Sigma Chemical Company.

\section{Animals}

Young (3-5 weeks old) and old (24 months old) female Wistar rats were employed. They were fed with standard rat food, given water and allowed to drink ad libitum and maintained on a $12 \mathrm{~h}$ light: $12 \mathrm{~h}$ darkness cycle. All the procedures were performed in accordance with the guidelines published in the National Institutes of Health Guide for the Care and Use of Laboratory Animals. All procedures involving animal and their care were performed at the Unit of Animal Care belonging to the Department of Biology, Biochemistry and Pharmacy at the University. The Animal Care Use Committee of this Unit approved the protocol used.

The absence of ovarian activity in old female rats was confirmed by daily controls of estrous cycle activity evaluated by optical microscope examination of vaginal smears. No estrous cycles were detected for at least 2-4 consecutive months (Selles et al. 2005).

\section{EC culture}

EC cultures were obtained from aortic ring explants isolated from young female Wistar rats (3-5 weeks old) (Yeh et al. 2002). When ECs of senile rats (senile ECs) were employed, aortic ring explants were isolated from aged Wistar rats (1.5-2 years old). Briefly, animals were killed by cervical dislocation and the full-length thoracic aorta was aseptically removed. Immediately after, the aorta was cleaned of adherent connective tissue and cut into small ring-shaped segments. Ring explants were seeded in $60 \mathrm{~mm}$ matrix-coated Petri dishes (NUNC) containing phenol red-free DMEM supplemented with 20\% (v/v) FCS, $60 \mu \mathrm{g} / \mathrm{ml}$ penicillin, $2.5 \mu \mathrm{g} / \mathrm{ml}$ amphotericin-B, $2 \mathrm{mM}$ L-glutamine, and $1.7 \mathrm{~g} / \mathrm{l}$ sodium bicarbonate. Explants were incubated at $37^{\circ} \mathrm{C}$ in $5 \% \mathrm{CO}_{2}$ atmosphere. In order to establish a pure EC culture, after 3 days of culture, the ring explants were removed and ECs were allowed to reach confluency. The identity of the ECs was determined i) by phase-contrast microscope observation of the characteristic morphology of cobblestone shape growth in confluent monolayer, ii) by positive immunocytochemistry reactivity to Factor VIII and to anti-Vimentin, clone V9 using the DakoCytomation EnVision system, and iii) by the bioability to synthesize NO (Campelo et al. 2012). Cells from passages 2-7 were used for all experiments. Fresh medium containing 10\% (v/v) FCS was replaced every $72 \mathrm{~h}$. Steroid solutions employed in the cellular treatments were prepared using isopropanol as a solvent. The final concentration of the vehicle was always below $0.1 \%(\mathrm{v} / \mathrm{v})$.

\section{Hematoxylin and eosin staining}

ECs were grown in $35 \mathrm{~mm}$ culture dishes (NUNC). Confluent ECs were washed twice with PBS and fixed with glutaraldehyde $(0.1 \%(\mathrm{v} / \mathrm{v}))$. The cells were stained with hematoxylin and eosin solution. Images were recorded using a digital camera (Olympus C7070WZ) coupled to an optical microscope (Olympus BX51).

\section{Immunofluorescence detection of vascular endothelial growth factor receptor 2 and CD34 expression}

ECs were grown in 96-well optical bottom plates (NUNC). Confluent ECs were washed twice with PBS and fixed with paraformaldehyde $2 \%(\mathrm{v} / \mathrm{v})$ in PBS for $15 \mathrm{~min}$. Then, the cells were permeabilized with $0.1 \%(\mathrm{v} / \mathrm{v})$ Triton X-100 in PBS for $10 \mathrm{~min}$ and incubated with $1 \%$ albumin for $1 \mathrm{~h}$ to prevent non-specific antibody binding. Cells were immunostained with anti-CD34 (8G12 BD Biosciences, San Jose, CA, USA) or anti-vascular endothelial growth factor receptor 2 (VEGFR2; FAB357P BD Biosciences). Cell nuclei were counterstained with 4-6-diamidino-2-phenylindole (DAPI; Sigma-Aldrich). Immunofluorescence was visualized using an Olympus BX51 microscope equipped with a Q-Color 3 digital camera (Olympus America, Center Valley, PA, USA).

\section{Platelet assays}

Platelet isolation For platelet aggregation assays, rat platelet-rich plasma (PRP) was obtained as described previously (Cutini et al. 2012). For platelet adhesion assays, PRP was fixed in $4 \%(\mathrm{v} / \mathrm{v})$ formaldehyde/PBS for 10 min, suspended in PBS ( $\mathrm{pH} 7.4$ ) at room temperature,

Published by Bioscientifica Ltd. 
and centrifuged at $750 \boldsymbol{g}$ for $10 \mathrm{~min}$. Then, fixed platelets were washed twice with PBS. Manual platelet counting was done using a hemacytometer. Finally, platelets were suspended at a final concentration of $5 \times 10^{6}$ platelets $/ \mathrm{ml}$ in DMEM supplemented with $1 \%(\mathrm{v} / \mathrm{v})$ FCS.

Platelet adhesion assay Confluent monolayers of ECs seeded on 24-multiwell culture plates (NUNC) were starved for $24 \mathrm{~h}$ with serum-free DMEM and then exposed to Pg, MPA, LPS $(1 \mu \mathrm{g} / \mathrm{ml})$, or steroids plus LPS in DMEM supplemented with $1 \%(\mathrm{v} / \mathrm{v})$ FCS. Once treatment was finished ECs were washed two times with PBS, and $300 \mu \mathrm{l}$ platelet suspension were added on pretreated cells. Platelets were allowed to adhere to ECs for $2 \mathrm{~h}$ at $37^{\circ} \mathrm{C}$. Supernatants of each well containing nonadhered platelets were collected and counted using a hemacytometer. The number of adhered platelets to ECs was calculated by difference between total added platelets and non-adherent platelets. Results are expressed as mean \pm s.D. of the number of adhered platelets/ $\mu l$.

Platelet aggregation assay Platelet aggregation was measured using a turbidimetric assay as described previously (Cutini et al. 2012). ECs were seeded on 24-multiwell culture plates (NUNC) at a density of $3 \times 10^{4}$ cells/well in DMEM supplemented with $10 \%(\mathrm{v} / \mathrm{v})$ FCS and allowed to grow to $60-70 \%$ of confluency. Culture medium was replaced by $400 \mu \mathrm{PRP}, 3 \times 10^{8}$ platelets $/ \mathrm{ml}$ ) and exposed to $10 \mathrm{nM} \mathrm{Pg}, 10 \mathrm{nM}$ MPA, or vehicle (control) for $5 \mathrm{~min}$. Immediately after treatment, $285 \mu \mathrm{l}$ PRP was taken and set in a CronoLog 430 aggregometer cuvette with continuous stirring. Aggregation was initiated by the addition of $2 \times 10^{-5} \mathrm{M}$ ADP. The control group containing ECs in PRP was treated with vehicle alone (isopropanol $<0.1 \%, \mathrm{v} / \mathrm{v}$ ). Changes in light transmission were recorded for $5 \mathrm{~min}$ after ADP addition. The signal generated by a platelet-poor plasma was used as the $100 \%$ transparent control (Kikuta et al. 1998). ECs were dissolved in $1 \mathrm{M} \mathrm{NaOH}$ and aliquots were taken for protein determination by Lowry's method. Results were expressed as percentages of IPA with respect to control values. The maximal platelet aggregation was considered to be that induced by the control samples. Two animals were used for each experiment. When the direct effect of progestins on platelets was evaluated, PRP was incubated with the Pg or MPA in the absence of ECs, and platelet aggregation was measured as described earlier. Basal aggregation was considered the maximal aggregation exhibited by PRP alone, without vehicle or steroid treatment. Results were expressed as percentages of platelet aggregation with respect to basal values.

\section{Measurement of NO production}

ECs were seeded on 24-multiwell culture plates (NUNC) at a density of $3.5 \times 10^{4}$ cells/well and allowed to grow to $90 \%$ of confluency in DMEM containing 10\% (v/v) FCS. Steroid treatment was performed in fresh DMEM containing $1 \%(\mathrm{v} / \mathrm{v})$ FCS by addition of Pg or MPA for 7 min. Respective controls (vehicle alone) were also processed. When specific antagonist/inhibitors were used, they were added $30 \mathrm{~min}$ before steroid treatment. Nitrites $\left(\mathrm{NO}_{2}^{-}\right)$were measured in the incubation media as a stable and non-volatile breakdown product of the NO released, employing the spectrometric Griess reaction (Campelo et al. 2012). Briefly, once treatment is finished, aliquots of culture medium supernatant were mixed with Griess reagent (1\% sulphanilamide and 0.1\% naphthylene diamine dihydrochloride in $2.5 \%$ phosphoric acid) and incubated $10 \mathrm{~min}$ at room temperature. Absorbance was measured at $548 \mathrm{~nm}$ in a microplate reader (Biotek Synergy-HT). The concentration of $\mathrm{NO}_{2}^{-}$in the samples was determined with reference to a sodium nitrite $\left(\mathrm{NaNO}_{2}\right)$ standard curve performed in the same matrix. Cells were dissolved in $1 \mathrm{M} \mathrm{NaOH}$ and protein content was measured by the Lowry method (Lowry et al. 1951). The results were expressed as nanomoles of $\mathrm{NO}_{2}^{-}$per mg protein.

\section{Cell migration assay}

Cells were seeded at a density of $5 \times 10^{5}$ cells $/ \mathrm{cm}^{2}$ in $60 \mathrm{~mm}$ NUNC dishes with DMEM containing 10\% (v/v) FCS and were grown to $90 \%$ confluency. Cells were starved for $24 \mathrm{~h}$ with serum-free medium. In order to evaluate cell migration, a wound was made by pressing a razor blade down on the dish and removing part of the monolayer (Pedram et al. 2002). Immediately after, adhered cells were washed twice with PBS and cultured in fresh DMEM containing 1\% (v/v) FCS plus Pg, MPA, or vehicle control. After $48 \mathrm{~h}$ of culture, cells were fixed with glutaraldehyde $0.1 \%(\mathrm{v} / \mathrm{v})$ and stained with Giemsa solution. Migration was quantified by counting the number of cell nuclei that migrated into the scratched area in at least seven different representative fields of each culture plate. Cell migration was recorded using a digital camera (Olympus C7070WZ) coupled to an optical microscope (Olympus BX51). Results are expressed as mean \pm s.D. of the number of migrated cells/field.

Published by Bioscientifica Ltd. 


\section{Crystal violet assay}

ECs were seeded on 96-multi-well plates (NUNC) at a density of $5 \times 10^{3}$ cells/well in DMEM supplemented with $10 \%(\mathrm{v} / \mathrm{v})$ FCS and allowed to grow to $60-70 \%$ confluency. Cells were synchronized by placing them in serum-free DMEM for $24 \mathrm{~h}$ and further exposed to different concentrations of Pg, MPA, or vehicle (control) for $24 \mathrm{~h}$ in fresh DMEM containing 1\% (v/v) FCS. Medium was removed, the cells were fixed in $1 \%$ glutaraldehyde for $15 \mathrm{~min}$, and subsequently stained for $30 \mathrm{~min}$ in $0.1 \%$ crystal violet. Immediately after, the cells were washed twice, air-dried, and dissolved in $0.2 \%$ Triton. Absorbance of each well was measured at $590 \mathrm{~nm}$ in a microplate reader (Biotek Synergy-HT). Cell viability was determined as optical density (OD) increase, and maximal viability was considered to be the OD registered from the control group. Results are expressed as percentages of cell viability with respect to control values.

\section{Statistical analysis}

The results presented were obtained from three independent experiments where each individual experimental condition was examined in quadruplicate $(n=4)$. All data are presented as mean \pm s.D. Different cell cultures were used for each independent experiment. Comparisons between two means were made using Student's $t$-test and multiple comparisons with one- or two-way ANOVA, followed by Fisher's least significant difference test, using SPSS Statistical software for Windows. $P$ values lower than 0.05 were considered to be statistically significant.

\section{Results}

Having in mind our previous reports using rat aortic tissue concerning the non-genomic action of Pg on NO synthesis (Selles et al. 2002, Mendiberri et al. 2006, Cutini et al. 2009), using isolated ECs, we studied the rapid regulation of NO production by different concentrations of Pg and MPA. To that end, cells were exposed to Pg or MPA for $7 \mathrm{~min}$. Figure $1 \mathrm{~A}$ shows that MPA treatment significantly inhibited NO synthesis with respect to control value (43, 40 , and $49 \%$ below the control value for 1,10 , and $100 \mathrm{nM}$ MPA respectively; $P<0.02$ ). On the other hand, when ECs were treated with the same concentrations of $\mathrm{Pg}$, a marked stimulus in the vasoactive synthesis was detected $(41,64$, and $96 \%$ above the control value for 1,10 , and $100 \mathrm{nM} \mathrm{Pg}$ respectively; $P<0.02$ ) (Fig. $1 \mathrm{~A}$ ). In order to determine whether Pg and MPA were affecting NOS-derived NO, we
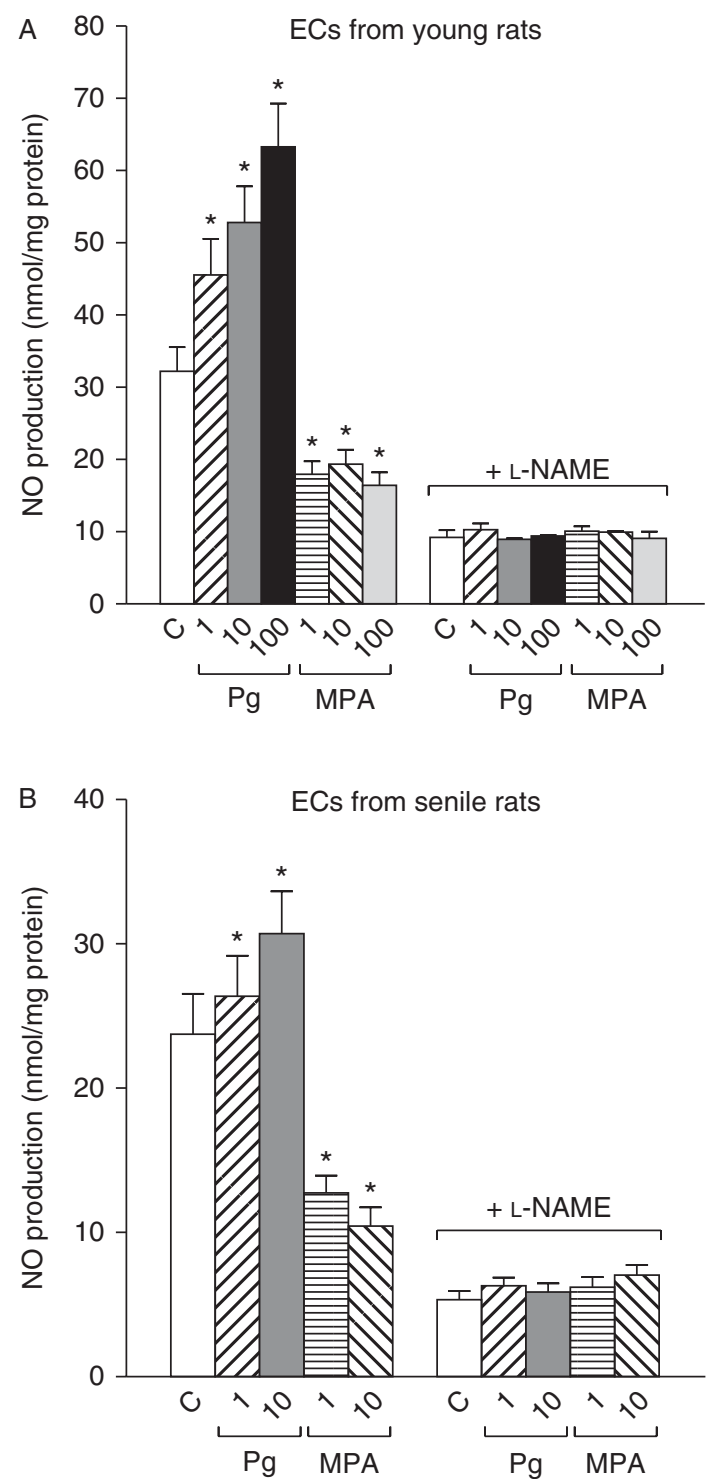

Figure 1

Effect of Pg and MPA on NO production in ECs. Starved ECs (A) and senile ECs (B) were preincubated $30 \mathrm{~min}$ in the absence or presence of $10 \mu \mathrm{M}$ L-NAME and then treated with Pg or MPA at the indicated concentrations for $7 \mathrm{~min}$. NO production was measured by the Griess reaction as described in Materials and methods. Results represent the average \pm s.D. of three independent experiments $(n=4)$. (C, control). ${ }^{\star} P<0.02$ vs control.

measured the rapid production of $\mathrm{NO}$ in the presence of an irreversible NOS inhibitor (L-NAME). As shown in Fig. 1A, $10 \mu \mathrm{M}$ L-NAME completely suppressed the effects evoked by the progestogens.

The effect of Pg and MPA on ECs viability was evaluated using the crystal violet assay. The results presented in Table 1 show that maximal cell viability was observed under all experimental conditions, ruling out a negative effect of progestins on cell survival.

Published by Bioscientifica Ltd. 
Table 1 Effect of Pg and MPA on EC viability

\begin{tabular}{lc} 
Treatment & Cell viability (percentage with respect to control) $^{\mathrm{a}}$ \\
\cline { 1 - 1 } $1 \mathrm{nM} \mathrm{Pg}$ & $99.8 \pm 8.9$ \\
$10 \mathrm{nM} \mathrm{Pg}$ & $102.4 \pm 7.4$ \\
$100 \mathrm{nM} \mathrm{Pg}$ & $90.15 \pm 6.3$ \\
$1 \mathrm{nM} \mathrm{MPA}$ & $101.8 \pm 5.9$ \\
$10 \mathrm{nM} \mathrm{MPA}$ & $103.4 \pm 5.4$ \\
$100 \mathrm{nM} \mathrm{MPA}$ & $98.5 \pm 6.3$ \\
\hline
\end{tabular}

${ }^{a}$ Subconfluent ECs were incubated in serum-free medium for $24 \mathrm{~h}$ and then treated with different concentrations of Pg, MPA, or vehicle (control group) for an additional $24 \mathrm{~h}$ in fresh DMEM containing $1 \%$ (v/v) FCS. Cell viability was measured by Crystal Violet assay as described in Materials and methods. The optical density (OD) value in the control group is considered to be $100 \%$. Values are the average \pm s.D. of three independent experiments performed in quadruplicate.
The effects of Pg and MPA were also tested in ECs isolated from senile rats devoid of ovarian activity. The stimulatory action of Pg markedly decreased; meanwhile, MPA maintained its ability to inhibit NO synthesis (Fig. 1B). Negative controls with L-NAME were also examined. We also checked the existence of phenotypic differences between ECs derived from young and senile rats. Figure 2 shows that similar morphological features (hematoxylin and eosin staining) and comparable EC marker expressions (VEGFR2; CD34) were found in both groups.

In order to evaluate the participation of PgR in the effects of steroids on NO production, we employed an antagonist of PgR, the compound RU486. ECs were

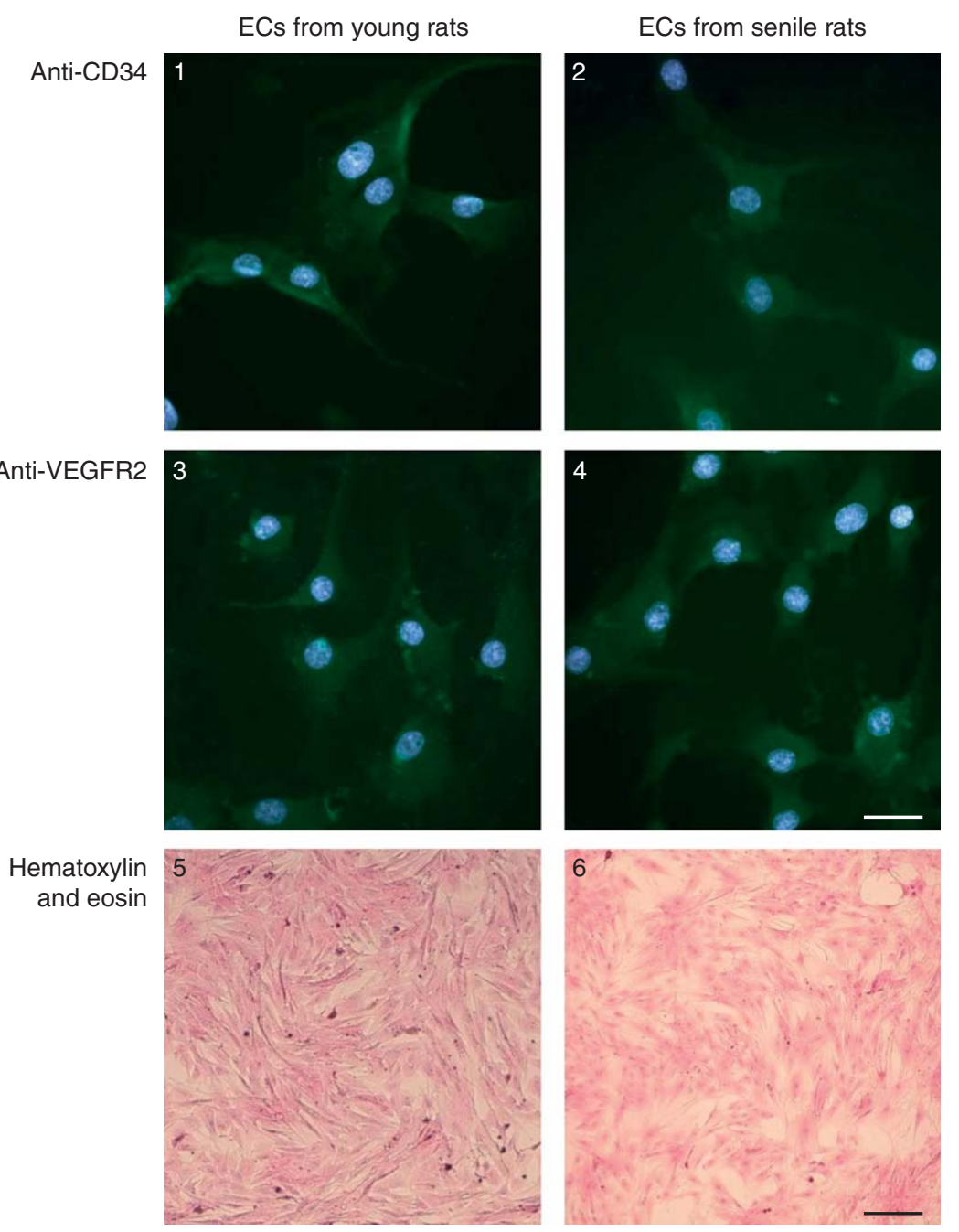

\section{Figure 2}

Characterization of EC derived from young and senile rats. Microphotographs show representative fields of ECs obtained from young or adult (senile) rats immunostained with anti-CD34 (1 and 2); anti-VEGFR2 (3 and 4) or stained with hematoxylin and eosin ( 5 and 6$)$. Cell nuclei were counterstained with DAPI (1-4). Details are described in Materials and methods. Magnification: $600 \times(1-4)$ and $100 \times(5$ and 6$)$. The scale bar in $1-4$ represents $25 \mu \mathrm{m}$. The scale bar in 5 and 6 represents $100 \mu \mathrm{m}$. http://joe.endocrinology-journals.org DOI: 10.1530/JOE-13-0263
() 2014 Society for Endocrinology Printed in Great Britain
Published by Bioscientifica Ltd. 


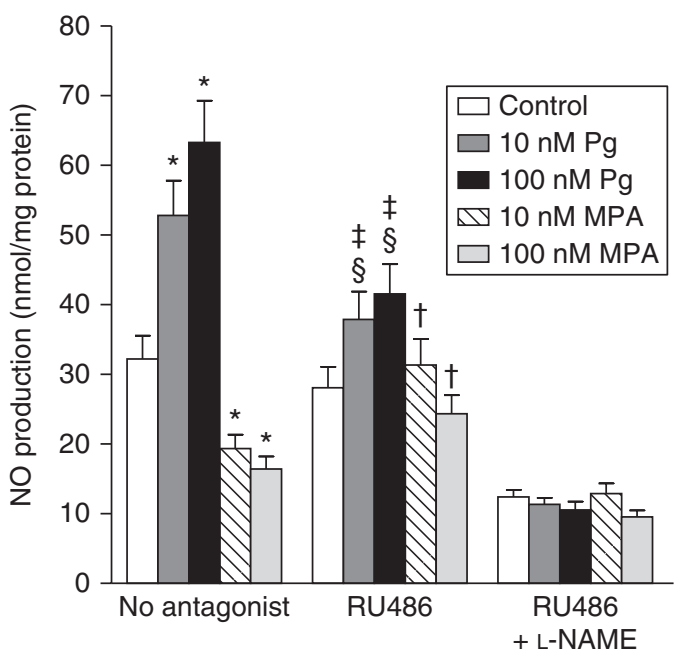

Figure 3

Effect of a PgR antagonist on the regulation by Pg and MPA of NO production. Starved ECs were preincubated $30 \mathrm{~min}$ in the absence or presence of $1 \mu \mathrm{M}$ RU486 or $1 \mu \mathrm{M}$ RU486 plus $10 \mu \mathrm{M}$ L-NAME and then exposed to Pg or MPA at the indicated concentrations for $7 \mathrm{~min}$. NO production was measured by Griess reaction as described in Materials and methods. Results represent the average $t$ s.D. of three independent experiments $(n=4)$. ${ }^{*} P<0.02$ vs control plus vehicle; ${ }^{\S} P<0.01$ vs each $P$; ${ }^{\ddagger} P<0.05$ vs control + RU486, ${ }^{\dagger} P<0.01$ vs each MPA.

preincubated $30 \mathrm{~min}$ with $1 \mu \mathrm{M}$ RU486 prior to steroid treatment. We obtained evidence that the antagonist affected the fast stimulatory or the inhibitory action on NO production exerted by Pg or MPA respectively (Fig. 3). The presence of the PgR antagonist partially suppressed the stimulatory action of Pg on NO synthesis (64 and 96\% vs 35 and $47 \%$ above control, Pg 10 and $100 \mathrm{nM}$ in the absence vs presence of RU486 respectively, $P<0.05$ ) (Fig. 3). Similar results were obtained when the cells were treated with $1 \mathrm{nM}$ Pg or $1 \mathrm{nM}$ MPA (data not shown). Simultaneous preincubation of ECs with RU486 and L-NAME prior to hormonal treatment blunted NO production (Fig. 3). We also evaluated the probable participation of androgen receptor (AR) using flutamide as $\mathrm{AR}$ antagonist. The presence of flutamide did not affect the action of progestin on NO synthesis (data not shown).

The involvement of protein kinase C (PKC), MAPK, and PI3K intracellular signaling transduction pathways in Pg and MPA regulation of vasoactive production was investigated. To that end, ECs were preincubated for 30 min in the absence or presence of LY294002 (a PI3K inhibitor), PD98059 (a MAPK inhibitor), or chelerythrine (a PKC inhibitor) before treatment with Pg or MPA.

The MEK inhibitor (PD98059) totally abolished the stimulatory action on NO synthesis elicited by $10 \mathrm{nM}$ Pg (Fig. 4A). On the other hand, the inhibition of the PKC signaling pathway with chelerythrine did not modify the stimulation on NO production induced by the natural progestogen. A partial reduction in Pg effect was observed in the presence of LY294002 (Fig. 4A). Similar results were obtained when hormonal treatments were performed with
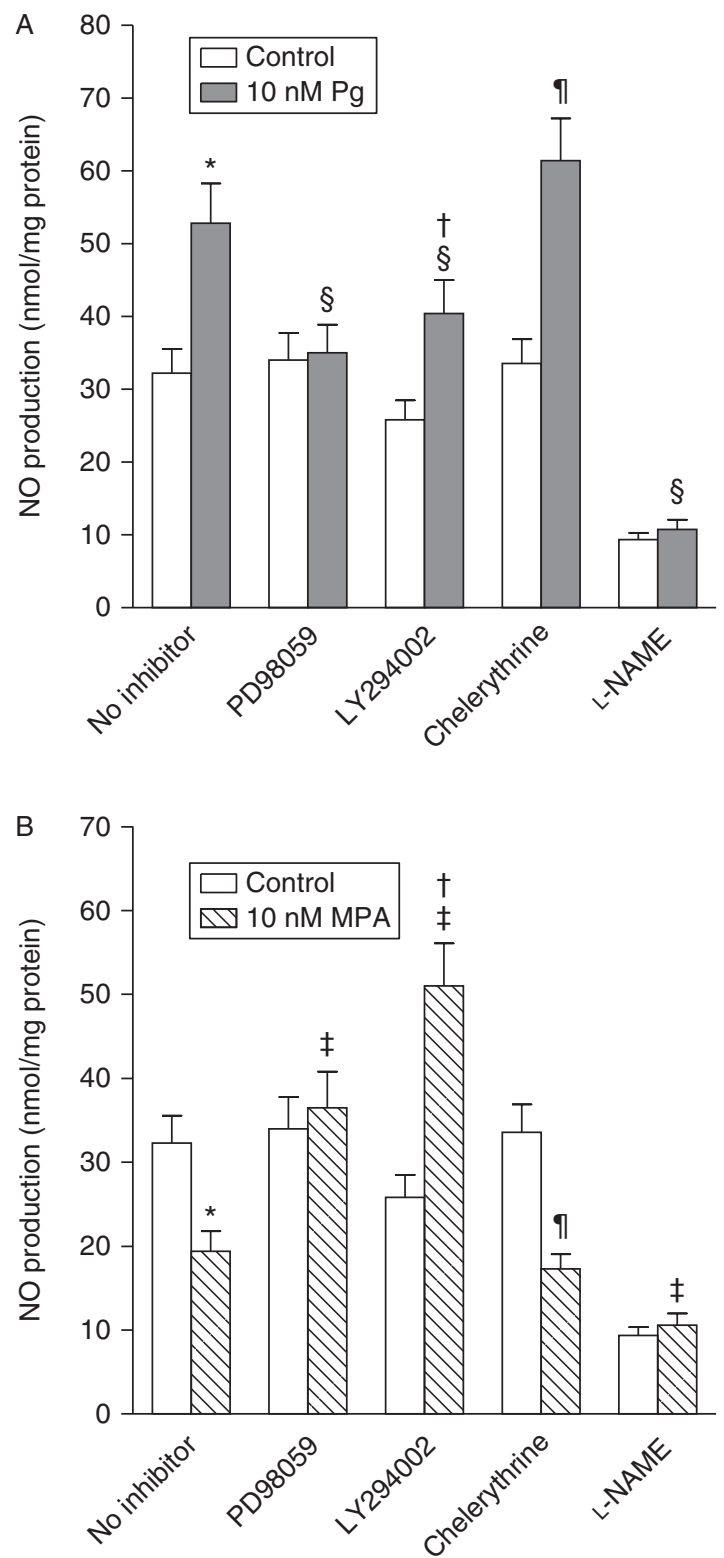

\section{Figure 4}

Involvement of MAPK, PI3K, and PKC signaling pathways in the regulation of NO production by Pg and MPA. Starved ECs were preincubated for $30 \mathrm{~min}$ in the absence or presence of $5 \mu \mathrm{M}$ PD98059, $1 \mu \mathrm{M}$ LY294002, $1 \mu \mathrm{M}$ chelerythrine, and $10 \mu \mathrm{M}$ L-NAME and then exposed to $10 \mathrm{nM} \mathrm{Pg}(\mathrm{A})$ or $10 \mathrm{nM}$ MPA (B) for $7 \mathrm{~min}$. NO production was measured by Griess reaction as described in Materials and methods. Results represent the average \pm s.D. of three independent experiments $(n=4) .{ }^{*} P<0.02$ vs control; ${ }^{\S} P<0.01$ vs $\mathrm{Pg} ;{ }^{\dagger} P<0.01$ vs control + LY294002; ${ }^{\top} P<0.02$ vs control + chelerythrine; ${ }^{\ddagger} P<0.01$ vs MPA. 


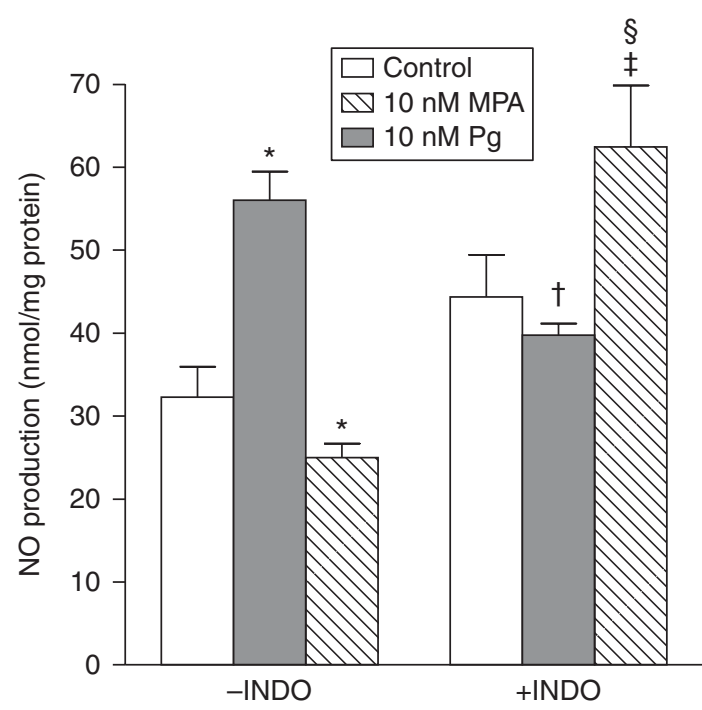

Figure 5

Involvement of COX signaling pathway on the regulation of NO production by Pg and MPA. Starved ECs were preincubated $30 \mathrm{~min}$ in the absence or presence of $10 \mu \mathrm{M}$ indomethacin (INDO) and then exposed to $10 \mathrm{nM} \mathrm{Pg}$ or $10 \mathrm{nM}$ MPA for $7 \mathrm{~min}$. NO production was measured by Griess reaction as described in Materials and methods section. Results represent the average \pm s.D. of three independent experiments $(n=4) .{ }^{*} P<0.02$ vs control;

${ }^{\dagger} P<0.01$ vs Pg; ${ }^{\S} P<0.01$ vs control plus indomethacin; ${ }^{\ddagger} P<0.01$ vs MPA.

1 or $100 \mathrm{nM} \mathrm{Pg}$, or in the presence of another PI3K inhibitor (Wortmannin) (data not shown).

As shown in Fig. 4B, the presence of PD98059 or LY294002 completely suppressed the inhibitory effect on NO production exerted by $10 \mathrm{nM}$ MPA treatment. It is noteworthy that the presence of the PI3K pathway inhibitor not only completely abolished the inhibitory effect of MPA on vasoactive synthesis but also enhanced NO production with respect to control values. As observed with Pg treatment, when ECs were pretreated with the PKC inhibitor, the action of $10 \mathrm{nM}$ MPA was not modified (Fig. 4B). Similar results were obtained when EC treatment was performed with 1 or $100 \mathrm{nM}$ MPA (data not shown). Again, the negative control performed using L-NAME confirmed the progestin's actions on NOS-derived NO (Fig. 4A and B).

Having in mind that our previous work demonstrated that in rat aortic strips the mechanism of action of Pg is dependent on a cross talk between COX and NOS pathways that involves COX stimulation of NOS synthesis (Selles et al. 2002), we performed additional experiments to test whether, in isolated ECs, the effect of progestins on NO production is dependent on COX activity. To that end, indomethacin was used as COX inhibitor. As shown in Fig. 5, pretreatment with indomethacin reversed the effect of Pg or MPA on NO synthesis. Printed in Great Britain
As NOS and COX end products can affect platelet function, in order to study whether the steroids were able to regulate platelet-ECs interactions, platelet adhesion and platelet aggregation assays were performed. Cells were incubated with Pg or MPA for $24 \mathrm{~h}$ in the presence or absence of a platelet adhesion inducer, bacterial LPS, which was added during the last $21 \mathrm{~h}$ of steroid treatment. Once treatment was finished, an exact number of platelets was seeded on EC monolayers and allowed to adhere for $2 \mathrm{~h}$. Figure $6 \mathrm{~A}$ shows that treatment with $\operatorname{Pg}(1,10$, and
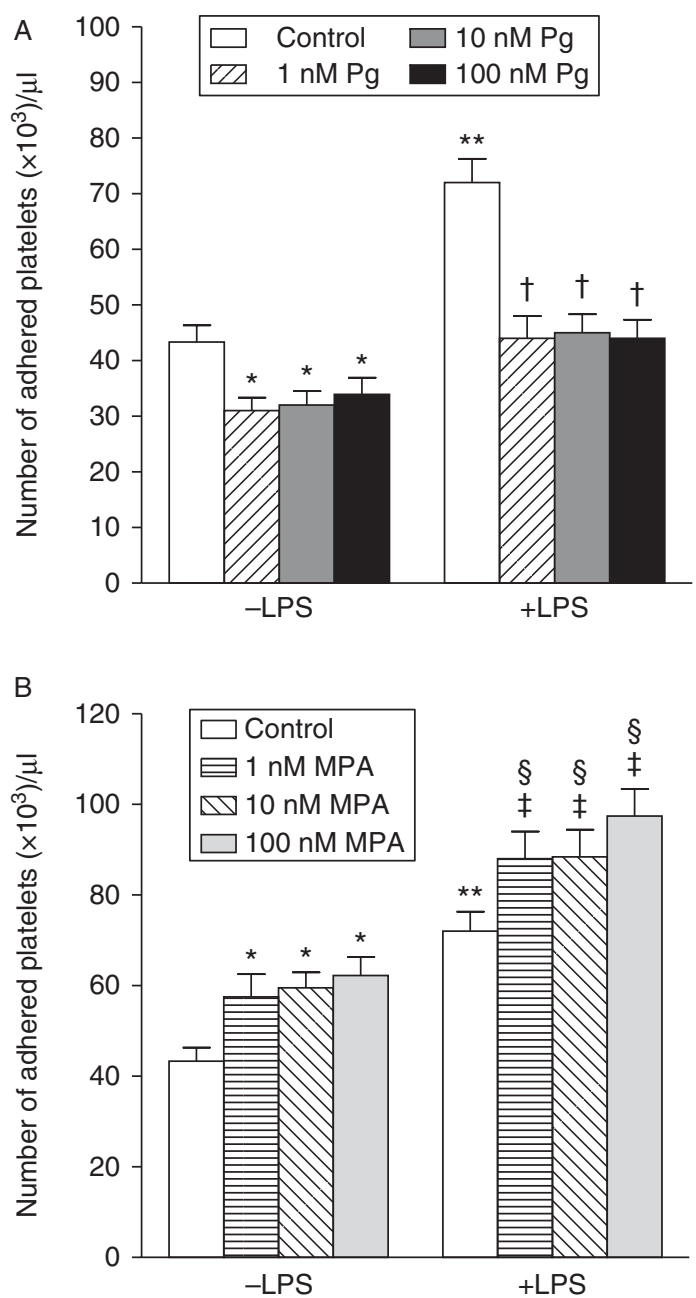

Figure 6

Effect of Pg and MPA on platelet adhesion to ECs. EC cultures were treated with Pg (A) or MPA (B) at the indicated concentrations for $24 \mathrm{~h}$ in the presence or absence of $1 \mu \mathrm{g} / \mathrm{ml}$ LPS, which was added during the last $21 \mathrm{~h}$ of hormonal treatment. Platelets were seeded on EC monolayer for $2 \mathrm{~h}$. Immediately after, the supernatant was removed and the platelets were counted as described in Materials and methods. Bars represent the means \pm S.D. of the number of adhered platelets/ $\mu$ l. Results are the average \pm s.D. of three independent experiments $(n=4) .{ }^{*} P<0.05$ vs control; $* * P<0.001$ vs control; ${ }^{\dagger} P<0.005$ vs LPS; ${ }^{\ddagger} P<0.02$ vs LPS; ${ }^{\S} P<0.001$ vs each MPA.

Published by Bioscientifica Ltd. 
$100 \mathrm{nM}$ ) significantly inhibited platelet adhesion to ECs with respect to the control $(29,26$, and $22 \%$ below the control values for 1,10 , and $100 \mathrm{nM}$ Pg respectively; $P<0.05)$. On the other hand, when cells were exposed to LPS, platelet adhesion was markedly increased (69\% above control, $P<0.001)$. However, pretreatment of ECs with 1 , 10 , and $100 \mathrm{nM}$ Pg totally abolished platelet adhesion induced by the proinflammatory agent (Fig. 6A). In contrast, treatment of cells with 1,10 , and $100 \mathrm{nM}$ MPA significantly increased platelet adhesion $(33,37$, and $44 \%$ above control values for 1,10 , and $100 \mathrm{nM}$ MPA respectively; $P<0.05$ ) (Fig. 6B). Moreover, we can see that, unlike Pg results, pretreatment of cells with MPA potentiated the stimulatory action of LPS on platelet adhesion (Fig. 6B).

To test the effect of progestins on platelet aggregation, ECs were incubated with PRP and subsequently exposed to Pg or MPA for $5 \mathrm{~min}$. Immediately, aliquots of PRP were transferred to the aggregometer and ADP-induced platelet aggregation was measured. Table 2 shows the quantitative data obtained. Similarly, as indicated by our previous data obtained with rat aortic strips (Selles et al. 2002), Pg exhibited a markedly antiaggregatory action; meanwhile, the IPA induced by MPA was lower ( 82.3 vs $27.2 \%$ IPA with respect to control values, Pg vs MPA). A direct action of the progestins on platelets was ruled out, as the addition of Pg or MPA to PRP in the absence of ECs induced maximal aggregation similar to basal group (Table 2).

Afterward, using wound-healing assays, we examined the effect of Pg and MPA on migration of ECs. Figure 7 shows that 48-h treatment with Pg induced a significant increase in the number of cells that crossed the wound border and migrated to removed area for a wide range of concentrations tested (5-100 nM). At lower doses (1 nM Pg),

Table 2 Effect of Pg and MPA on platelet aggregation

\begin{tabular}{|c|c|c|}
\hline Treatment & $\begin{array}{c}\text { Percentage of inhibition } \\
\text { of platelet aggregation } \\
\text { with respect to control } \\
\text { values }\end{array}$ & $\begin{array}{c}\text { Percentage of platelet } \\
\text { aggregation with } \\
\text { respect to basal } \\
\text { values }^{\mathrm{b}}\end{array}$ \\
\hline 10 nM Pg & $82.3 \pm 6.2 *$ & $97.5 \pm 6.5$ \\
\hline 10 nM MPA & $27.2 \pm 2.3^{\dagger}$ & $98.2 \pm 7.3$ \\
\hline
\end{tabular}

${ }^{*} P<0.01$ and ${ }^{\dagger} P<0.05$ with respect to control values.

${ }^{a}$ Culture medium was replaced by PRP and cells were exposed to $10 \mathrm{nM} \mathrm{Pg}$, $10 \mathrm{nM}$ MPA, or vehicle (control) for $5 \mathrm{~min}$. PRP was rapidly removed and platelet aggregation was measured as described in Materials and methods. Results are expressed as percentages of inhibition of platelet aggregation with respect to the control group (ECs plus vehicle alone) and are the average \pm S.D. of three independent experiments $(n=4)$.

${ }^{b}$ Aliquots of PRP (in the absence of ECs) were incubated with $10 \mathrm{nM} \mathrm{Pg}$ or $10 \mathrm{nM}$ MPA for $5 \mathrm{~min}$. The basal group received vehicle alone. Immediately after ADP was added, platelet aggregation was measured. Results are expressed as percentages with respect to basal aggregation and represent the average \pm s.D. of three independent experiments $(n=4)$. no significant differences were detected in the number of migrant cells with respect to the control group (Fig. 7).

When the synthetic progestin was assayed, the evidence indicates that MPA also increased cell migration to the denuded area compared with non-treated cells at all concentrations tested (Fig. 8).

The magnitude of the incremental increase induced by MPA was much higher than the stimulatory action elicited by Pg (1168 vs $275 \%$; $10 \mathrm{nM}$ MPA vs $10 \mathrm{nM}$ Pg respectively, $P<0.001$ ) (Figs 7 and 8). Finally, Fig. 9 shows a schematic diagram that summarizes the results obtained.

\section{Discussion}

The data presented in this research provide evidence of differential regulation of vascular function by Pg and MPA. Pg markedly stimulates NO production; meanwhile, MPA inhibits its synthesis. Although Pg and MPA exhibit divergent effects on the vasoactive molecule generation, both mechanisms of action involve at least in part, the participation of PgR, COX, PI3K, and MAPK signal transduction pathways. Under inflammatory conditions, Pg prevents platelet adhesion to ECs. In contrast, MPA potentiates platelet adhesion. Both steroids enhance cell migration in a wide range of concentration.

Divergent actions of Pg and MPA have been previously shown using human umbilical vein ECs (HUVECs; Simoncini et al. 2004). In contrast, having in mind that atherosclerosis mainly affect arteries, we focused our attention on the progestins vascular actions on aortic ECs. Endothelial NO bioavailability plays a pivotal role in the maintenance of vascular homeostasis. Impairment of NO production seriously compromises vascular health and represents a risk factor for disease development (Duckles \& Miller 2010). We showed that Pg and MPA have opposite effects on NO production in ECs. Physiological concentrations of Pg rapidly stimulate, whereas MPA inhibits NO production. The blocking of progestin's effects with L-NAME confirms that Pg and MPA affect NOS-derived NO. Evidence reported in the literature shows that Pg increases NO synthesis in human ECs by transcriptional and non-transcriptional mechanisms, whereas MPA lacks such actions (Simoncini et al. 2006). Furthermore, chronic administration of Pg to ovariectomized rats restores the endothelial control of vascular tone in mesenteric arterial rings through the endothelial formation of NO; MPA failed to do that (Chataigneau et al. 2004). On the basis of this line of evidence, we found that in ECs isolated from rats devoid of ovarian activity, MPA maintained its inhibitory action on NOS synthesis.

Published by Bioscientifica Ltd 
A

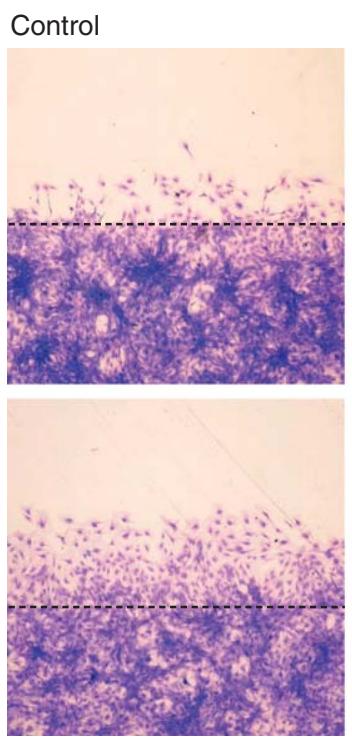

$10 \mathrm{nM} \mathrm{Pg}$
$1 \mathrm{nM} \mathrm{Pg}$
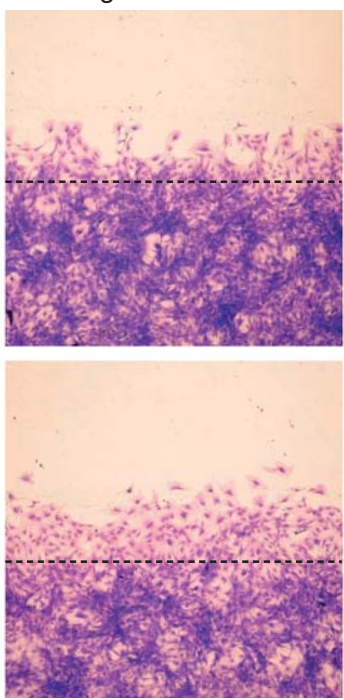

$50 \mathrm{nM} \mathrm{Pg}$
$5 \mathrm{nM} \mathrm{Pg}$
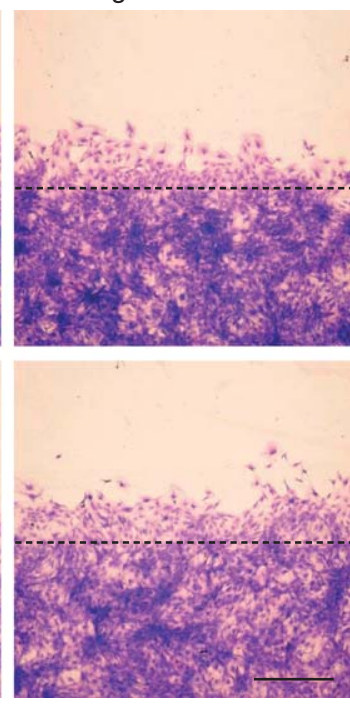

$100 \mathrm{nM} \mathrm{Pg}$

B

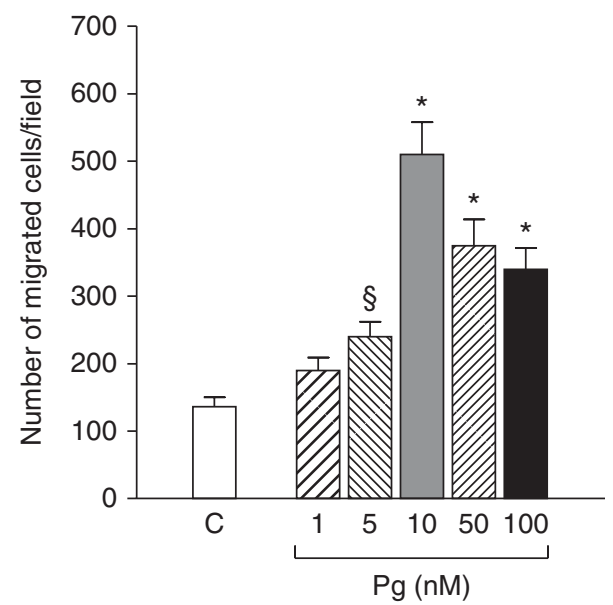

\section{Figure 7}

Effect of Pg on EC migration. Confluent EC cultures were serum starved for $24 \mathrm{~h}$, and cells were removed by scraping. Detached cells were washed with $\mathrm{PBS}$, and the remaining monolayer was treated during $48 \mathrm{~h}$ with $\mathrm{Pg}$ at the indicated concentrations or with vehicle (control). Dotted lines indicate the boundary between the unscratched and scratched areas. (A) Images

It is known that blood vessels express functional PgR (Perrot-Applanat et al. 1988), which would be regulated by Pg as well as by synthetic progestins, like MPA (Sitruk-Ware 2000). The involvement of PgR in cellular and molecular effects of MPA and Pg at the vascular level has been reported. In HUVECs, the PgR antagonist RU486 caused reduction of the inhibitory action of MPA on $\mathrm{E}_{2}$-induced endothelial NOS (eNOS) phosphorylation and eNOS activity (Oishi et al. 2011). In HUVECs, Pg and MPA decreased thromboxane A2 release and enhanced show representative fields of each condition after Giemsa staining $(40 \times$ magnification). The scale bar represents $300 \mu \mathrm{m}$. (B) Bars show the means and S.D. of number of migrated cells/field from three separate experiments performed in quadruplicate. ${ }^{*} P<0.001$ vs control (C); ${ }^{\S} P<0.01$ vs control.

prostacyclin synthase gene and protein expression in a PgR-dependent manner (Oviedo et al. 2011). MPA antagonizes the $\mathrm{E}_{2}$ stimulation of VEGF expression in human endometrial stromal cells through a mechanism of action that involves the PgR (Okada et al. 2011). Using RU486 as a PgR antagonist, we obtained evidence that PgR participates in the fast action of both steroids on NO synthesis regulation, with slight differences. The decrease in NO production induced by MPA was completely abolished by RU486. However, the enhancement of the vasoactive

Published by Bioscientifica Ltd. 
A

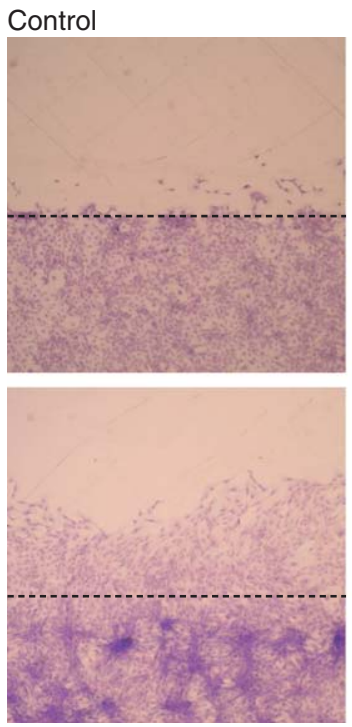

10 nM MPA
1 nM MPA
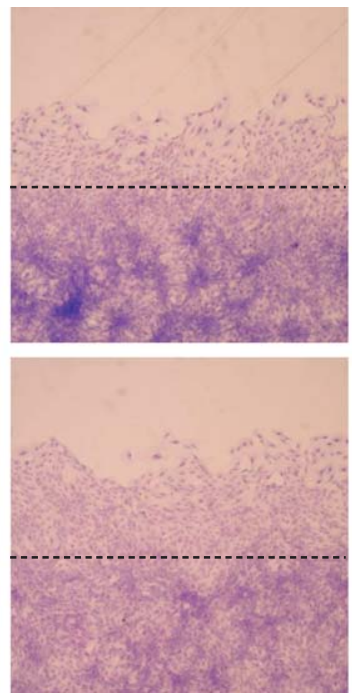

$50 \mathrm{nM}$ MPA
5 nM MPA
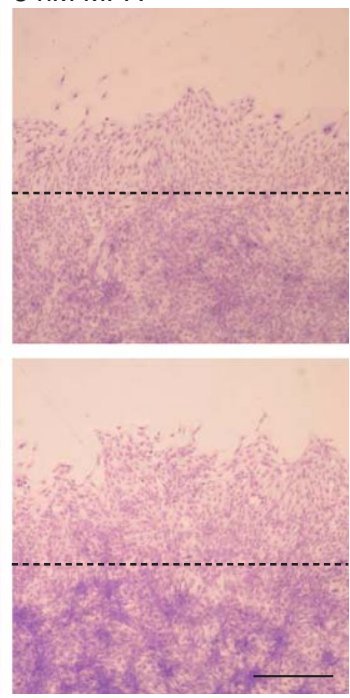

100 nM MPA

B

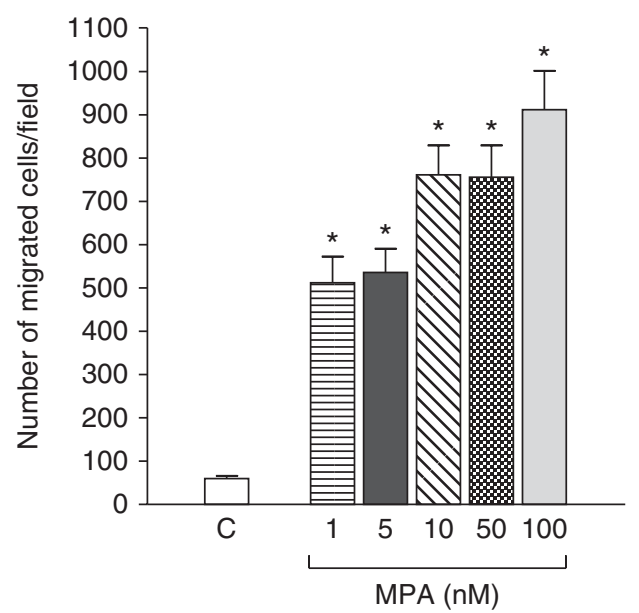

\section{Figure 8}

Effect of MPA on ECs migration. Confluent EC cultures were serum starved for $24 \mathrm{~h}$ and cells were removed by scraping. Detached cells were washed with PBS and the remaining monolayer was treated for $48 \mathrm{~h}$ with MPA at the indicated concentrations or with vehicle (control). Dotted lines indicate the boundary between the unscratched and scratched areas. (A) Images

release elicited by Pg was partially dependent on PgR. Although this evidence indicates the participation of PgR in the opposite effect on NO production, it remains to determine be determined whether the steroid effects involve isoforms A or B of PgR, as well as the possible participation of a membrane-anchored receptor, which has been recently described (Zhu et al. 2003).

The activity of eNOS is regulated by changes in intracellular calcium and phosphorylation. After agonist stimulation, the enhancement in cytosolic calcium leads show representative fields of each condition after Giemsa staining $(40 \times$ magnification). The scale bar represents $300 \mu \mathrm{m}$. (B) Bars show the means and S.D. of number of migrated cells/field from three separate experiments performed in quadruplicate. ${ }^{\star} P<0.001$ vs control.

to calmodulin binding to eNOS and subsequent phosphorylation. The enzymes responsible for phosphorylation status depend on the primary stimulus. Several intracellular signaling systems, such as AC/PKA, PLC/PKC, PI3K/Akt, CaMKII, and MAPK, have been shown to be involved in the hormonal regulation of eNOS activity (Forstermann 2010). Indeed, protein phosphatase 1 (PP1) and protein phosphatase $2 \mathrm{~A}$ (PP2A) also participate (Ladurner et al. 2012). Employing selective kinase inhibitors, we found that the mechanism of action

Published by Bioscientifica Ltd. 


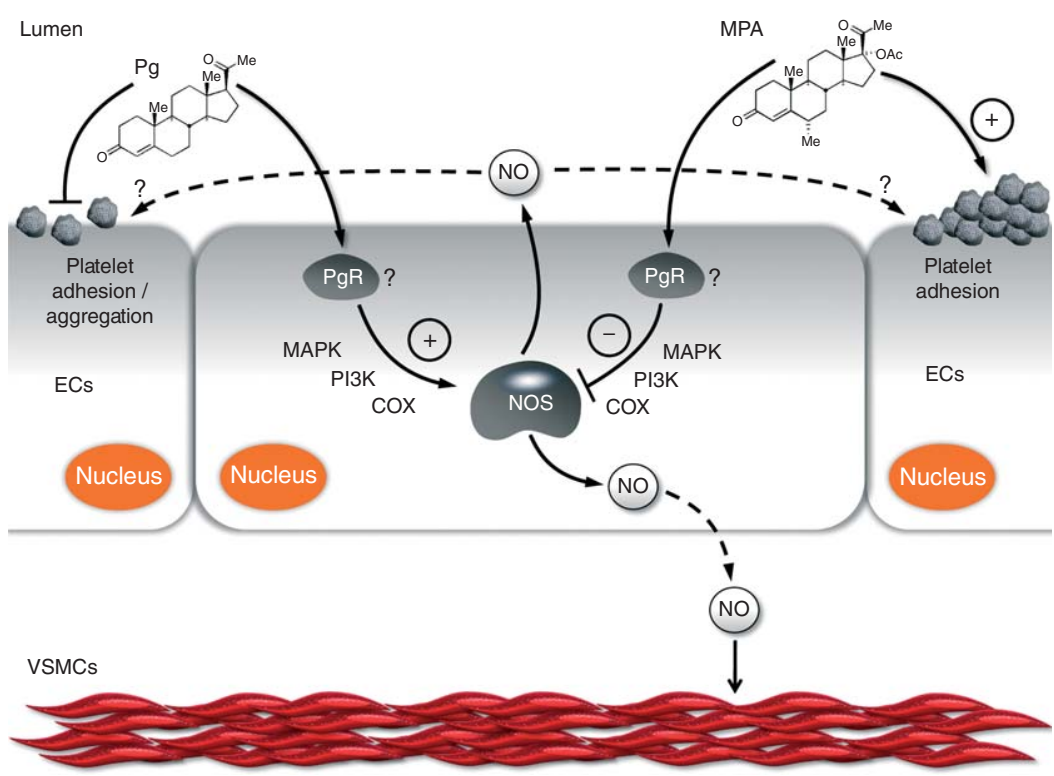

\section{Figure 9}

Schematic representation of differential regulation of vascular function elicited by Pg and MPA. Pg stimulates while MPA inhibits endothelial NO production. The mechanisms of action involve PI3K, MAPK, and COX signal transduction pathways and participation of PgR. The subtype of PgR involved remains to be established. Pg inhibits platelet aggregation

displayed by Pg and MPA on the regulation of endothelial NO production was dependent on MAPK pathway and independent of PKC activation. Indeed, PI3K was partially involved in Pg action; meanwhile, the presence of LY294002 not only suppressed the inhibitory effect of MPA but also enhanced NO synthesis with respect to control values. In hippocampal neurons, both Pg and MPA activate p44/p42MAPK (ERK) signaling pathway, Pg quickly and transiently activates nuclear ERK, while MPA-activated ERK remains cytosolic without a nuclear signal (Nilsen \& Brinton 2003). MPA induces cell proliferation through upregulation of cyclin D1 expression via the PI3K/Akt/NF- $\kappa \mathrm{B}$ cascade in human breast cancer cells (Saitoh et al. 2005) or drives PgR to interact with tyrosine kinase c-Src and to activate the PI3K signaling pathway, leading to the activation of the RhoA/ROCK-2 signaling system (Fu et al. 2008b). In human ECs, divergent effects of MPA and Pg with a patent difference in the recruitment of MAPK and PI3K signal transduction pathways have been reported (Simoncini et al. 2006). Taking into account the fact that we have previously reported that Pg stimulates COX activity, we also tested the feasibility of participation of the COX system in Pg and MPA action in NO production. Cross talk between NOS and COX systems has been proposed. Although there is a plethora of evidence in the literature and adhesion to CEs, whereas MPA stimulates platelet-EC interactions. NO generated by the ECs diffuses to the tunica media in order to regulate vascular tone or may be released to the vascular lumen affecting platelet function. COX, cyclooxygenase; PgR, progesterone receptor; NO, nitric oxide.

suggesting that increased NO stimulates COX-2, the interaction between NO and prostaglandin is not unidirectional and upregulation of NOS activity by COX has also been reported (Salvemini 1997, Kim 2011). In rat Kupffer cells and in platelets, indomethacin significantly reduced NOS activity (Gaillard et al. 1992, Chen et al. 1997). Our data indicate that the same intracellular pathways are implicated in opposite effects on NO synthesis elicited by each progestin. Based on the results obtained, a possible explanation for the mechanism of action involved would be that MAPK and PI3K regulate NOS activity directly or through the modulation of COX activity. However, the results presented in this work cannot establish the sequence of the signal transduction pathway activation. It has been reported that in HUVECs and in brain microvascular ECs, PI3K/Akt and MAPK pathways are involved in COX expression and activation (Garonna et al. 2011, Hsieh et al. 2012). Indeed, in HUVECs, MPA stimulates COX activity (Hermenegildo et al. 2005). Having in mind the complexity of the intracellular signaling system, with multiple network interconnections between the different routes, a cross talk between different signal transduction pathways that eventually leads to the activation or inhibition of eNOS may occur. Moreover, considering that we have previously demonstrated that PP1 and PP2A participate in

Published by Bioscientifica Ltd. 
the non-genomic action of $\mathrm{Pg}$ in rat aortic rings (Mendiberri et al. 2006, Cutini et al. 2009), the possible participation of phosphatase pathways should not be ruled out. Further experiments are required in order to fully understand the signaling pathways involved in progestin NOS regulation.

When the effect of progestins on platelet-ECs interaction was evaluated, we found that Pg exerts an inhibitory effect on platelet adhesion to the endothelium and in turn prevents the adhesion induced by an inflammatory environment (presence of LPS). Pg also exerts a potent antiaggregatory effect. Thus, the action of Pg may be considered a beneficial fact that contributes to avoiding the earlier stages of vascular injury. On the other hand, we suggest that the synthetic progestin is associated with a potentially pro-atherogenic effect, as MPA stimulates platelet adhesion and also potentiates the effect exerted by the presence of LPS and exhibited a slight antiaggregatory action compared with Pg. These results represent the first evidence, to our knowledge, of a direct action of MPA on platelet-EC interactions. The data obtained in platelet aggregation assays indicate that the progestins indirectly modulate platelet aggregation through each direct action on ECs, probably due to the regulation of EC release of proaggregatory or antiaggregatory vasoactives, such as thromboxane, NO, and prostacyclin, that modulate platelet function. The findings that the mechanism of action elicited by each progestin involves NOS and COX transduction systems may support this interpretation. Platelet and monocyte adhesion to endothelium are events modulated through the expression of CAMs. It has been reported that in HUVECs, Pg prevents the expression of the protein and mRNA of TNF- $\alpha$-induced vascular cell adhesion molecule- 1 (VCAM-1), but MPA does not reverse the action of TNF- $\alpha$ (Otsuki et al. 2001). In peripheral and cerebral vasculature, MPA causes endothelial disruption, accumulation of monocytes in the vessel wall, and platelet activation; Pg does not show such toxicity (Thomas et al. 2003).

EC proliferation and migration contribute to the development of new capillaries, tissue remodeling, and repair. Using wound-healing assays, we demonstrated that Pg and MPA stimulate EC migration to the denuded area, at a wide range of concentrations. In agreement with our results, Fu et al. (2008a) showed that Pg and MPA enhance EC migration via the actin-binding protein moesin. Moreover, Pg promotes EC movement via the rapid regulation of the focal adhesion kinase (FAK; Zheng et al. 2012). In breast cancer, Pg and MPA promote cell movement via rapid actin cytoskeleton remodeling, which are mediated by moesin activation, events triggered by the extracellular small GTPase RhoA/Rho-associated kinase (ROCK-2) cascade through partially differing pathways by both steroids (Fu et al. 2008b).

A link between NO production and cell migration has been reported. NO stimulates human neural progenitor cell migration via cGMP-mediated signal transduction (Tegenge et al. 2011). Moreover, NO is critically involved in human EC migration (Schwalm et al. 2010). In contrast, plasma $\beta_{2}$-glycoprotein I inhibits EC migration through eNOS activation (Chiu et al. 2012). Although MPA and Pg have opposite effects on NO generation, they exhibit similar effects on EC migration. The explanation for this dual effect remains to be established.

In summary, the results discussed in this paper contribute to providing information for the comprehension of Pg and MPA regulation of relevant cellular and molecular events of vascular homeostasis. Although it has been assumed that some synthetic progestins used in HRT protocols exert similar clinical actions to natural Pg, both progestogens elicit specific cellular effects. The different pharmacokinetics of natural or synthetic progestins and their diverse affinities for the PgR may lead to the recruitment of partially divergent signaling pathways due to differential modulation of the receptor. The evidence reported to date on the true role of natural Pg and its potential clinical utility is insufficient and unraveling its mechanism of action remains a challenge. Further investigations are required for a complete understanding of the similarities or divergences of natural and synthetic progestins' vascular actions.

\section{Declaration of interest}

The authors declare that there is no conflict of interest that could be perceived as prejudicing the impartiality of the research reported.

\section{Funding}

This research was supported by grants from the Secretaría General de Ciencia y Tecnología (SGCyT), Universidad Nacional del Sur, Argentina (PGI 24/B159), and Consejo Nacional de Investigaciones Científicas y Técnicas (CONICET, Argentina, PIP N8 0356). P H C and A E C are recipient of graduate and postdoctoral fellowship respectively from CONICET.

\section{References}

van Baal WM, Kenemans P, Emeis JJ, Schalkwijk CG, Mijatovic V, van der Mooren MJ, Vischer UM \& Stehouwer CD 1999 Long-term effects of combined hormone replacement therapy on markers of endothelial function and inflammatory activity in healthy postmenopausal women. Fertility and Sterility 71 663-670. (doi:10.1016/S00150282(98)00513-5) 
Campelo AE, Cutini PH \& Massheimer VL 2012 Cellular actions of testosterone in vascular cells: mechanism independent of aromatization to estradiol. Steroids 77 1033-1040. (doi:10.1016/j.steroids.2012. 05.008)

Cartwright JE, Johnstone AP \& Whitley GS 2000 Endogenously produced nitric oxide inhibits endothelial cell growth as demonstrated using novel antisense cell lines. British Journal of Pharmacology 131 131-137. (doi:10.1038/sj.bjp.0703539)

Chataigneau T, Zerr M, Chataigneau M, Hudlett F, Hirn C, Pernot F \& Schini-Kerth VB 2004 Chronic treatment with progesterone but not medroxyprogesterone acetate restores the endothelial control of vascular tone in the mesenteric artery of ovariectomized rats. Menopause 11 255-263. (doi:10.1097/01.GME.0000097847.95550.E3)

Chen L, Salafranca MN \& Mehta JL 1997 Cyclooxygenase inhibition decreases nitric oxide synthase activity in human platelets. American Journal of Physiology 273 H1854-H1859.

Chiu WC, Chiou TJ \& Chiang AN $2012 \beta_{2}$-Glycoprotein I inhibits endothelial cell migration through the nuclear factor $\kappa \mathrm{B}$ signalling pathway and endothelial nitric oxide synthase activation. Biochemical Journal 445 125-133. (doi:10.1042/BJ20111383)

Choy JC, Granville DJ, Hunt DW \& McManus BM 2001 Endothelial cell apoptosis: biochemical characteristics and potential implications for atherosclerosis. Journal of Molecular and Cellular Cardiology 33 1673-1690. (doi:10.1006/jmcc.2001.1419)

Cutini PH \& Massheimer VL 2010 Role of progesterone on the regulation of vascular muscle cells proliferation, migration and apoptosis. Steroids 75 355-361. (doi:10.1016/j.steroids.2010.01.017)

Cutini P, Selles J \& Massheimer V 2009 Cross-talk between rapid and long term effects of progesterone on vascular tissue. Journal of Steroid Biochemistry and Molecular Biology 115 36-43. (doi:10.1016/j.jsbmb. 2009.02.014)

Cutini PH, Campelo AE, Agriello E, Sandoval MJ, Rauschemberger MB \& Massheimer VL 2012 The role of sex steroids on cellular events involved in vascular disease. Journal of Steroid Biochemistry and Molecular Biology 132 322-330. (doi:10.1016/j.jsbmb.2012.08.001)

Duckles SP \& Miller VM 2010 Hormonal modulation of endothelial NO production. Pflügers Archiv: European Journal of Physiology 459 841-851. (doi:10.1007/s00424-010-0797-1)

Forstermann U 2010 Nitric oxide and oxidative stress in vascular disease. Pflügers Archiv: European Journal of Physiology 459 923-939. (doi:10.1007/s00424-010-0808-2)

Fu XD, Flamini M, Sanchez AM, Goglia L, Giretti MS, Genazzani AR \& Simoncini T 2008a Progestogens regulate endothelial actin cytoskeleton and cell movement via the actin-binding protein moesin. Molecular Human Reproduction 14 225-234. (doi:10.1093/molehr/gan010)

Fu XD, Giretti MS, Baldacci C, Garibaldi S, Flamini M, Sanchez AM, Gadducci A, Genazzani AR \& Simoncini T 2008b Extra-nuclear signaling of progesterone receptor to breast cancer cell movement and invasion through the actin cytoskeleton. PLOS ONE $\mathbf{3}$ e2790. (doi:10.1371/journal.pone.0002790)

Gaillard T, Mulsch A, Klein H \& Decker K 1992 Regulation by prostaglandin $\mathrm{E}_{2}$ of cytokine-elicited nitric oxide synthesis in rat liver macrophages. Biological Chemistry Hoppe-Seyler 373 897-902. (doi:10.1515/bchm3. 1992.373.2.897)

Garonna E, Botham KM, Birdsey GM, Randi AM, Gonzalez-Perez RR \& Wheeler-Jones CP 2011 Vascular endothelial growth factor receptor-2 couples cyclo-oxygenase- 2 with pro-angiogenic actions of leptin on human endothelial cells. PLOS ONE 6 e18823. (doi:10.1371/journal. pone.0018823)

Glusa E, Graser T, Wagner S \& Oettel M 1997 Mechanisms of relaxation of rat aorta in response to progesterone and synthetic progestins. Maturitas 28 181-191. (doi:10.1016/S0378-5122(97)00057-1)

Grady D, Herrington D, Bittner V, Blumenthal R, Davidson M, Hlatky M, Hsia J, Hulley S, Herd A, Khan S et al. 2002 Cardiovascular disease outcomes during 6.8 years of hormone therapy: Heart and Estrogen/ progestin Replacement Study follow-up (HERS II). Journal of the American Medical Association 288 49-57. (doi:10.1001/jama.288.1.49)

Harrison DG, Widder J, Grumbach I, Chen W, Weber M \& Searles C 2006 Endothelial mechanotransduction, nitric oxide and vascular inflammation. Journal of Internal Medicine 259 351-363. (doi:10.1111/ j.1365-2796.2006.01621.x)

Hermenegildo C, Oviedo PJ, Garcia-Martinez MC, Garcia-Perez MA, Tarin JJ \& Cano A 2005 Progestogens stimulate prostacyclin production by human endothelial cells. Human Reproduction 20 1554-1561. (doi:10.1093/humrep/deh803)

Hsieh HL, Lin CC, Chan HJ, Yang CM \& Yang CM 2012 c-Src-dependent EGF receptor transactivation contributes to ET-1-induced COX-2 expression in brain microvascular endothelial cells. Journal of Neuroinflammation 9 152. (doi:10.1186/1742-2094-9-152)

Hulley S, Grady D, Bush T, Furberg C, Herrington D, Riggs B \& Vittinghoff E 1998 Randomized trial of estrogen plus progestin for secondary prevention of coronary heart disease in postmenopausal women. Heart and Estrogen/progestin Replacement Study (HERS) Research Group. Journal of the American Medical Association 280 605-613. (doi:10.1001/jama.280.7.605)

Ignarro LJ 1989 Biological actions and properties of endothelium-derived nitric oxide formed and released from artery and vein. Circulation Research 65 1-21. (doi:10.1161/01.RES.65.1.1)

Jiang CW, Sarrel PM, Lindsay DC, Poole-Wilson PA \& Collins P 1992 Progesterone induces endothelium-independent relaxation of rabbit coronary artery in vitro. European Journal of Pharmacology 211 163-167. (doi:10.1016/0014-2999(92)90524-8)

Joswig M, Hach-Wunderle V, Ziegler R \& Nawroth PP 1999 Postmenopausal hormone replacement therapy and the vascular wall: mechanisms of $17 \beta$-estradiol's effects on vascular biology. Experimental and Clinical Endocrinology \& Diabetes 107 477-487. (doi:10.1055/s-0029-1232556)

Kikuta K, Sawamura T, Miwa S, Hashimoto N \& Masaki T 1998 High-affinity arginine transport of bovine aortic endothelial cells is impaired by lysophosphatidylcholine. Circulation Research 83 1088-1096. (doi:10.1161/01.RES.83.11.1088)

Kim SF 2011 The role of nitric oxide in prostaglandin biology; update. Nitric Oxide 25 255-264. (doi:10.1016/j.niox.2011.07.002)

Ladurner A, Schmitt CA, Schachner D, Atanasov AG, Werner ER, Dirsch VM \& Heiss EH 2012 Ascorbate stimulates endothelial nitric oxide synthase enzyme activity by rapid modulation of its phosphorylation status. Free Radical Biology \& Medicine 52 2082-2090. (doi:10.1016/j.freeradbiomed. 2012.03.022)

L'hermite M, Simoncini T, Fuller S \& Genazzani AR 2008 Could transdermal estradiol + progesterone be a safer postmenopausal HRT? A review Maturitas 60 185-201. (doi:10.1016/j.maturitas.2008.07.007)

Lowry OH, Rosebrough NJ, Farr AL \& Randall RJ 1951 Protein measurement with the Folin phenol reagent. Journal of Biological Chemistry 193 265-275.

Manson JE, Hsia J, Johnson KC, Rossouw JE, Assaf AR, Lasser NL, Trevisan M, Black HR, Heckbert SR, Detrano R et al. 2003 Estrogen plus progestin and the risk of coronary heart disease. New England Journal of Medicine 349 523-534. (doi:10.1056/NEJMoa030808)

Mendiberri J, Rauschemberger MB, Selles J \& Massheimer V 2006 Involvement of phosphoinositide-3-kinase and phospholipase C transduction systems in the non-genomic action of progesterone in vascular tissue. International Journal of Biochemistry \& Cell Biology 38 288-296. (doi:10.1016/j.biocel.2005.09.012)

Moreno PR, Sanz J \& Fuster V 2009 Promoting mechanisms of vascular health: circulating progenitor cells, angiogenesis, and reverse cholesterol transport. Journal of the American College of Cardiology $\mathbf{5 3}$ 2315-2323. (doi:10.1016/j.jacc.2009.02.057)

Nilsen J \& Brinton RD 2003 Divergent impact of progesterone and medroxyprogesterone acetate (Provera) on nuclear mitogen-activated protein kinase signaling. PNAS 100 10506-10511. (doi:10.1073/ pnas.1334098100) 
Oishi A, Takahashi K, Ohmichi M, Mochizuki Y, Inaba N \& Kurachi H 2011 Role of glucocorticoid receptor in the inhibitory effect of medroxyprogesterone acetate on the estrogen-induced endothelial nitric oxide synthase phosphorylation in human umbilical vein endothelial cells. Fertility and Sterility 95 1168-1170. (doi:10.1016/j.fertnstert. 2010.09.041)

Okada H, Okamoto R, Tsuzuki T, Tsuji S, Yasuda K \& Kanzaki H 2011 Progestins inhibit estradiol-induced vascular endothelial growth factor and stromal cell-derived factor 1 in human endometrial stromal cells. Fertility and Sterility 96 786-791. (doi:10.1016/j.fertnstert.2011.06.048)

Otsuki M, Saito H, Xu X, Sumitani S, Kouhara H, Kishimoto T \& Kasayama S 2001 Progesterone, but not medroxyprogesterone, inhibits vascular cell adhesion molecule-1 expression in human vascular endothelial cells. Arteriosclerosis, Thrombosis, and Vascular Biology 21 243-248. (doi:10.1161/01.ATV.21.2.243)

Oviedo PJ, Sobrino A, Novella S, Rius C, Laguna-Fernandez A, Garcia-Perez MA, Tarin JJ, Cano A \& Hermenegildo C 2011 Progestogens reduce thromboxane production by cultured human endothelial cells. Climacteric 14 41-48. (doi:10.3109/13697131003602496)

Pedram A, Razandi M, Aitkenhead M, Hughes CC \& Levin ER 2002 Integration of the non-genomic and genomic actions of estrogen. Membrane-initiated signaling by steroid to transcription and cell biology. Journal of Biological Chemistry 277 50768-50775. (doi:10.1074/ jbc.M210106200)

Perrot-Applanat M, Groyer-Picard MT, Garcia E, Lorenzo F \& Milgrom E 1988 Immunocytochemical demonstration of estrogen and progesterone receptors in muscle cells of uterine arteries in rabbits and humans. Endocrinology 123 1511-1519. (doi:10.1210/endo-123-3-1511)

Ross R 1999 Atherosclerosis - an inflammatory disease. New England Journal of Medicine 340 115-126. (doi:10.1056/NEJM1999011 43400207)

Rossouw JE, Anderson GL, Prentice RL, LaCroix AZ, Kooperberg C, Stefanick ML, Jackson RD, Beresford SA, Howard BV, Johnson KC et al. 2002 Risks and benefits of estrogen plus progestin in healthy postmenopausal women: principal results From the Women's Health Initiative randomized controlled trial. Journal of the American Medical Association 288 321-333. (doi:10.1001/jama.288.3.321)

Saitoh M, Ohmichi M, Takahashi K, Kawagoe J, Ohta T, Doshida M, Takahashi T, Igarashi H, Mori-Abe A, Du B et al. 2005 Medroxyprogesterone acetate induces cell proliferation through up-regulation of cyclin D1 expression via phosphatidylinositol 3-kinase/Akt/nuclear factor- $\kappa \mathrm{B}$ cascade in human breast cancer cells. Endocrinology 146 4917-4925. (doi:10.1210/en.2004-1535)

Salvemini D 1997 Regulation of cyclooxygenase enzymes by nitric oxide. Cellular and Molecular Life Sciences 53 576-582. (doi:10.1007/ s000180050074)

Schwalm S, Pfeilschifter J \& Huwiler A 2010 Sphingosine kinase 1 is critically involved in nitric oxide-mediated human endothelial cell migration and tube formation. British Journal of Pharmacology 160 1641-1651. (doi:10.1111/j.1476-5381.2010.00818.x)

Selles J, Polini N, Alvarez C \& Massheimer V 2002 Nongenomic action of progesterone in rat aorta: role of nitric oxide and prostaglandins. Cellular Signalling 14 431-436. (doi:10.1016/S0898-6568(01)00265-0)

Selles J, Polini N, Alvarez C \& Massheimer V 2005 Novel action of estrone on vascular tissue: regulation of NOS and COX activity. Steroids 70 251-256. (doi:10.1016/j.steroids.2004.10.012)

Simoncini T, Mannella P, Fornari L, Caruso A, Varone G \& Genazzani AR 2003 In vitro effects of progesterone and progestins on vascular cells. Steroids 68 831-836. (doi:10.1016/j.steroids.2003.08.006)

Simoncini T, Mannella P, Fornari L, Caruso A, Willis MY, Garibaldi S, Baldacci C \& Genazzani AR 2004 Differential signal transduction of progesterone and medroxyprogesterone acetate in human endothelial cells. Endocrinology 145 5745-5756. (doi:10.1210/en.2004-0510)

Simoncini T, Caruso A, Garibaldi S, Fu XD, Giretti MS, Baldacci C, Scorticati C, Fornari L, Mannella P \& Genazzani AR 2006 Activation of nitric oxide synthesis in human endothelial cells using nomegestrol acetate. Obstetrics \& Gynecology 108 969-978. (doi:10.1097/01.AOG.0000233184.64531.84)

Sitruk-Ware R 2000 Progestins and cardiovascular risk markers. Steroids 65 651-658. (doi:10.1016/S0039-128X(00)00174-4)

Tegenge MA, Rockel TD, Fritsche E \& Bicker G 2011 Nitric oxide stimulates human neural progenitor cell migration via cGMP-mediated signal transduction. Cellular and Molecular Life Sciences 68 2089-2099. (doi:10.1007/s00018-010-0554-9)

Thomas T, Rhodin J, Clark L \& Garces A 2003 Progestins initiate adverse events of menopausal estrogen therapy. Climacteric 6 293-301. (doi:10.1082/cmt.6.4.293.301)

Tsao PS, Lewis NP, Alpert S \& Cooke JP 1995 Exposure to shear stress alters endothelial adhesiveness. Role of nitric oxide. Circulation 92 3513-3519. (doi:10.1161/01.CIR.92.12.3513)

Vazquez F, Rodriguez-Manzaneque JC, Lydon JP, Edwards DP, O'Malley BW \& Iruela-Arispe ML 1999 Progesterone regulates proliferation of endothelial cells. Journal of Biological Chemistry 274 2185-2192. (doi:10.1074/jbc.274.4.2185)

Yeh YC, Hwang GY, Liu IP \& Yang VC 2002 Identification and expression of scavenger receptor SR-BI in endothelial cells and smooth muscle cells of rat aorta in vitro and in vivo. Atherosclerosis 161 95-103. (doi:10.1016/ S0021-9150(01)00642-6)

Zheng S, Huang J, Zhou K, Xiang Q, Zhang Y, Tan Z, Simoncini T, Fu X \& Wang T 2012 Progesterone enhances vascular endothelial cell migration via activation of focal adhesion kinase. Journal of Cellular and Molecular Medicine 16 296-305. (doi:10.1111/j.1582-4934.2011. 01305.x)

Zhu Y, Rice CD, Pang Y, Pace M \& Thomas P 2003 Cloning, expression, and characterization of a membrane progestin receptor and evidence it is an intermediary in meiotic maturation of fish oocytes. PNAS $\mathbf{1 0 0}$ 2231-2236. (doi:10.1073/pnas.0336132100)

Received in final form 4 November 2013

Accepted 3 December 2013

Accepted Preprint published online 3 December 2013 http://joe.endocrinology-journals.org DOI: 10.1530/JOE-13-0263
(C) 2014 Society for Endocrinology Printed in Great Britain
Published by Bioscientifica Ltd. 